\title{
GESTÃO DE ACERVO ARQUEOLÓGICO HERDADO: RIO DO MEIO, UM ESTUDO DE CASO
}

\author{
Letícia da Silva Gondim ${ }^{1}$ \\ Luciane Zanenga Scherer ${ }^{2}$ \\ Simon-Pierre Nöel Robert Gilson ${ }^{3}$
}

\section{RESUMO}

Este artigo tem como objetivo apresentar uma reflexão sobre gestão de acervo herdado relacionado ao sítio arqueológico Rio do Meio, escavado entre os anos de 1996 e 1998, e que desde então se encontra armazenado nas reservas técnicas e em outros espaços pertencentes ao Museu de Arqueologia e Etnologia Professor Oswaldo Rodrigues Cabral, da Universidade Federal de Santa Catarina (MArquE/UFSC).

PALAVRAS-CHAVE: arqueologia, acervo herdado, conservação, museologia.

\section{ABSTRACT}

This paper aims to present a reflection on inherited collection management related with the archaeological site Rio do Meio, excavated between 1996 and 1998 and which has since been stored in the technical reserves and other spaces belonging to the Museum of Archaeology and Ethnology Professor Oswaldo Rodrigues Cabral, Federal University of Santa Catarina (MArquE/UFSC)

KEYWORDS: archaeology, inherited collection, conservation, museology.

\section{RESUMEN}

Este artículo tiene como objetivo presentar una reflexión sobre gestión de acervo heredado relacionado al sitio arqueológico Rio do Meio, excavado entre los años 1996 y 1998 y que desde entonces se encuentra almacenado en los depósitos de arqueología y otros espacios pertenecientes al Museo de Arqueologia e Etnologia Professor Oswaldo Rodrigues Cabral, de la Universidade Federal de Santa Catarina (MArquE/UFSC).

PALABRAS CLAVE: arqueología, acervo heredado, conservación, museología.

\footnotetext{
${ }^{1}$ Historiadora e graduanda em Museologia pela Universidade Federal de Santa Catarina (UFSC). Email: leticiasgondim@gmail.com.

2 Arqueóloga do MArquE; especialização em Paleopatologia, História e Evolução das Doenças Humanas (Fiocruz/RJ); mestrado em Arqueologia (Museu Nacional/RJ); doutoranda em Arqueologia (Museu Nacional (RJ).E-mail: luciane.z.s@ufsc.br/luscherer@gmail.com.

${ }^{3}$ Doutorando em Arqueologia no Museu Nacional-UFRJ (PPGArq), colaborador LEIA (UFSC). E-mail: simonp.gilson@gmail.com.

\begin{tabular}{|l|l|l|l|l|l|l|}
\hline (c) Rev. Arqueologia Pública & Campinas, SP & v.11 & n.2 & p. 83 & Novembro/2017 & ISSN 2237-8294 \\
\hline
\end{tabular}
}




\section{INTRODUÇÃO}

O sítio arqueológico Rio do Meio, situado na praia de Jurerê da llha de Santa Catarina, foi escavado em caráter de salvamento, entre os anos de 1996 e 1998, pela equipe do Museu Universitário Professor Oswaldo Rodrigues Cabral (MU/UFSC), atual MArquE/UFSC. A pesquisa, coordenada pela então arqueóloga da instituição, visava mitigar os danos causados ao sítio por conta de um empreendimento imobiliário de responsabilidade da empresa Habitasul, e sua escavação estava prevista em Minuta de Acordo em Ação Pública de Responsabilidade, movida pelo Ministério Público Federal (FOSSARI, 1998, p. 11).

As amostras de sedimentos coletadas na época não haviam sido processadas nem sequer triadas, encontrando-se nas mesmas embalagens plásticas em que foram recolhidas na década de 1990, ou seja, em situação inapropriada de acondicionamento, correspondendo a uma grande quantidade e diversidade de material arqueológico herdado pela Instituição. Nessa perspectiva, consideramos como acervo herdado aqueles materiais reunidos em pesquisas arqueológicas e que, no entanto, não foram processados adequadamente, achando-se da mesma forma em que foram trazidos de campo, e cujo arqueólogo responsável pela escavação não se encontra mais na instituição para finalizar o processo.

O sítio Rio do Meio, entendido como acervo herdado e aqui debatido como estudo de caso, é caracterizado como um sítio raso com cerâmica, terminologia que segundo Lessa (LESSA 2005; LESSA\&SCHERER, 2008) não é a única usada para essa tipologia de sítio, o que gerou, e ainda gera, extensos debates entre pesquisadores. De fato, na literatura os sítios rasos podem ser encontrados sob várias designações: Jazidas paleoetnográficas, acampamento litorâneo e sambaqui sujo (LESSA, 2005; LESSA\&SCHERER, 2008; PROUS, 1992). Entretanto, o presente artigo não tem pretensão de discutir as diferentes terminologias aplicadas a esta tipologia de sítio arqueológico.

Para dar conta dessa problemática, foi encaminhado um projeto para concorrer ao Prêmio Elisabete Anderle de Estímulo à Cultura, 2014, Prêmio Catarinense de Museus Elisabete Anderle, Modalidade de Pesquisa, concedido pela Fundação Catarinense de Cultura (FCC), sob o título "Revisitando o acervo arqueológico do sítio Rio do Meio: estudo das coleções cerâmica, faunística e lítica". Aprovado em primeiro lugar, o projeto transcorreu por um ano e meio e, mesmo assim, ainda estão sendo realizados trabalhos em cima da coleção. Além disso, como o MArquE, atualmente, busca um diálogo entre seus diferentes profissionais (SCHERER, 2016), as formas de execução desse projeto foram discutidas entre os profissionais da arqueologia, museologia e conservação da instituição. 


\section{ARQUEOLOGIA POR CONTRATO}

A arqueologia por contrato, também conhecida como arqueologia de salvamento, preventiva ou empresarial, engloba uma série de medidas de proteção, resgate e valorização do patrimônio arqueológico ameaçado pelo desenvolvimento econômico atual. Ao longo dos últimos anos, a referida arqueologia evoluiu muito com a publicação de novas Portarias, culminando na Instrução Normativa № 001, do Instituto do Patrimônio Histórico e Artístico Nacional (IPHAN), o que tornou ainda mais rigorosas as metodologias aplicadas para esse tipo de pesquisa e seus consequentes desdobramentos. É fundamental esclarecer que o sítio Rio do Meio foi escavado numa época em que a arqueologia por contrato, então conhecida como arqueologia de salvamento, dava seus primeiros passos, e as metodologias aplicadas neste campo ainda não estavam consolidadas.

A Arqueologia de Salvamento, segundo Morais em artigo publicado na Revista do Museu de Arqueologia e Etnologia da Universidade de São Paulo (MAE/USP), em 1995, mesma década em que ocorreu a escavação do sítio Rio do Meio, era por ele considerada uma modalidade carente de sistemática metodológica consolidada, sendo possível perceber que este era um tema pertinente debatido entre a comunidade de arqueólogos. $O$ autor ainda ressalta que, por algumas décadas, ela foi implementada de muitas maneiras e, por isso, ficou bastante suscetível a lacunas e críticas das mais variadas devido à falta do emprego de metodologias adequadas. Nesse momento, prevaleceu o aspecto quantitativo, ou seja, a ideia de que quanto mais material arqueológico coletado e quanto mais sítios descobertos, melhor seria o resultado da pesquisa. Sua crítica é bastante relevante, pois aponta que na gana de buscar quantidade,

materiais arqueológicos são coletados sem nenhuma contextualização vertical ou horizontal ou, pior, estruturas arqueológicas conexas (como os solos antropogênicos de habitações) são consideradas individualmente, cada qual como um sítio arqueológico (sítio-"habitação"). Mormente isso leva à aquisição de dados inconsistentes, mesmo falsos, comprometendo a interpretação do design da ocupação humana. (MORAIS, 1995, p. 79).

Portanto, a metodologia de coleta adotada para a escavação do sítio Rio do Meio ia ao encontro daquilo que era então difundido entre os arqueólogos da época, cuja preocupação maior era coletar o máximo de acervo antes do sítio ser totalmente destruído. Porém, com o tempo, ficou claro que esse tipo de coleta não era adequado e nem estava em harmonia com outras áreas que atuam, interdisciplinarmente, junto à arqueologia como a museologia e a conservação -, e que o aspecto quantitativo se tornou um sério 


\section{ARTIGO}

\section{Revista de Arqueologia Pública}

problema, ainda possível de ser percebido nos dias atuais, acarretando diversas dificuldades para a instituição responsável pela salvaguarda do acervo.

\subsection{METOdOLOGIA DE ESCAVAÇÃO E POLÍTICA DE COLETA DO SÍTIO RIO DO MEIO}

Como metodologia de trabalho, a arqueóloga responsável pela pesquisa optou por escavar o sítio arqueológico Rio do Meio a partir de camadas naturais, com a implementação de um quadriculamento em duas áreas de escavação, perfazendo um total de 260 quadrículas escavadas com uma profundidade que variava de $60 \mathrm{~cm}$ a $90 \mathrm{~cm}$. 0 material coletado, peneirado no sítio em malhas de $1 \mathrm{~mm}$ ou $2 \mathrm{~mm}$, foi levado em sua totalidade para o laboratório de arqueologia, parcialmente processado e, posteriormente, encaminhado às reservas técnicas do então Museu Universitário (MU/UFSC). Além disso, uma amostra de sedimento de cada nível e de cada quadrícula foi coletada. Quando não foi possível escavar uma quadrícula, devido aos imperativos de tempo ligado a um trabalho de salvamento, seu conteúdo foi levado integralmente para o museu a fim de passar por um processo de flotação e triagem em laboratório (FOSSARI, 1998, 2004) e, como veremos a seguir, nunca foi realizado por aquela equipe.

Por outro lado, durante esse trabalho de campo os pesquisadores tiveram a preocupação de registrar o máximo de informações, o que oferece, hoje, uma grande diversidade de fontes primárias, como croquis, fotos e mapas. É de se notar que, atualmente, estas se encontram digitalizadas, sendo possível, portanto, sua consulta sem o manuseio dos originais.

O sítio Rio do Meio foi escavado seguindo um método de campo, porém, como Morais (1995) ressaltou, não houve uma reflexão maior sobre a política de coleta, e uma enorme quantidade de material foi levada para o museu. A preocupação em coletar material era tão grande que até mesmo parte do lixo moderno, encontrado na superfície do sítio, foi transportado para o laboratório e acondicionado em reserva técnica. Estes detalhes tornamse importantes para que se tenha uma noção geral da quantidade de material encaminhado ao museu, que, por sua vez, gerou diversos problemas, diagnosticáveis até o momento, como reservas técnicas abarrotadas de materiais que já deveriam ter sido descartados, mesmo em campo, tornando estes espaços locais depósitos de acervo mal conservado e documentado, dentre outras inúmeras enfermidades. 


\section{EM QUAIS CONDIÇÕES ENCONTRA-SE O ACERVO?}

Os vestígios, artefatos e sedimentos coletados durante a escavação do sítio Rio do Meio estão atualmente armazenados parte em reserva técnica do MArquE (apenas o material flotado, triado e analisado), e parte (amostras não triadas, incluindo grande quantidade de acervo malacológico) em edificação pertencente ao Museu (uma réplica de Engenho de Farinha), ou seja, em condições inadequadas, mas inevitáveis de armazenamento seja pela falta de espaço, seja pela falta de mão de obra, não tendo os profissionais do museu condições de processar e armazenar tamanho volume de material sem a participação efetiva de outros pesquisadores e estudantes de graduação e pósgraduação. O material que se encontra armazenado no Engenho permanece acondicionado em sacos plásticos e/ou sacolas de mercado, muitas vezes fragilizadas e mesmo rompidas.

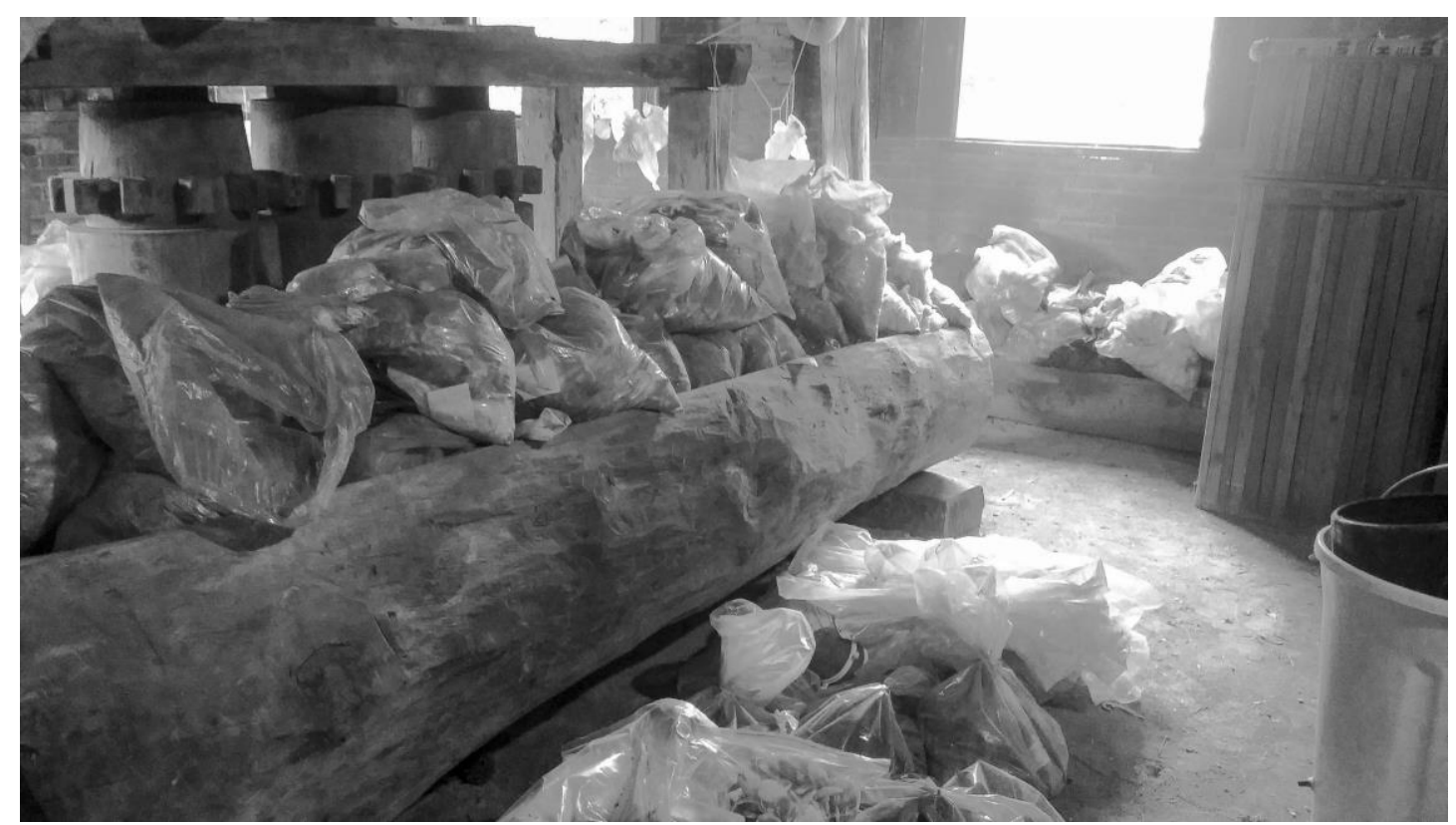

Figura 1: Engenho de farinha onde se encontra armazenada grande parte do material proveniente do sítio Rio do Meio.

Foto: Letícia Gondim/Acervo: MArquE/UFSC (2017).

As informações sobre cada quadrícula, nível e data de coleta foram anotadas em caneta hidrocor diretamente nas embalagens plásticas, e com o passar dos anos estas informações desapareceram integral ou parcialmente. A forma como foram coletadas e acondicionadas em campo sugere que esta coleta foi feita pensando, de fato, num tratamento rápido em laboratório, o que não ocorreu. Muitas vezes, as identificações 
anotadas, bem como as inúmeras informações são de difícil compreensão, como exemplificadas abaixo:

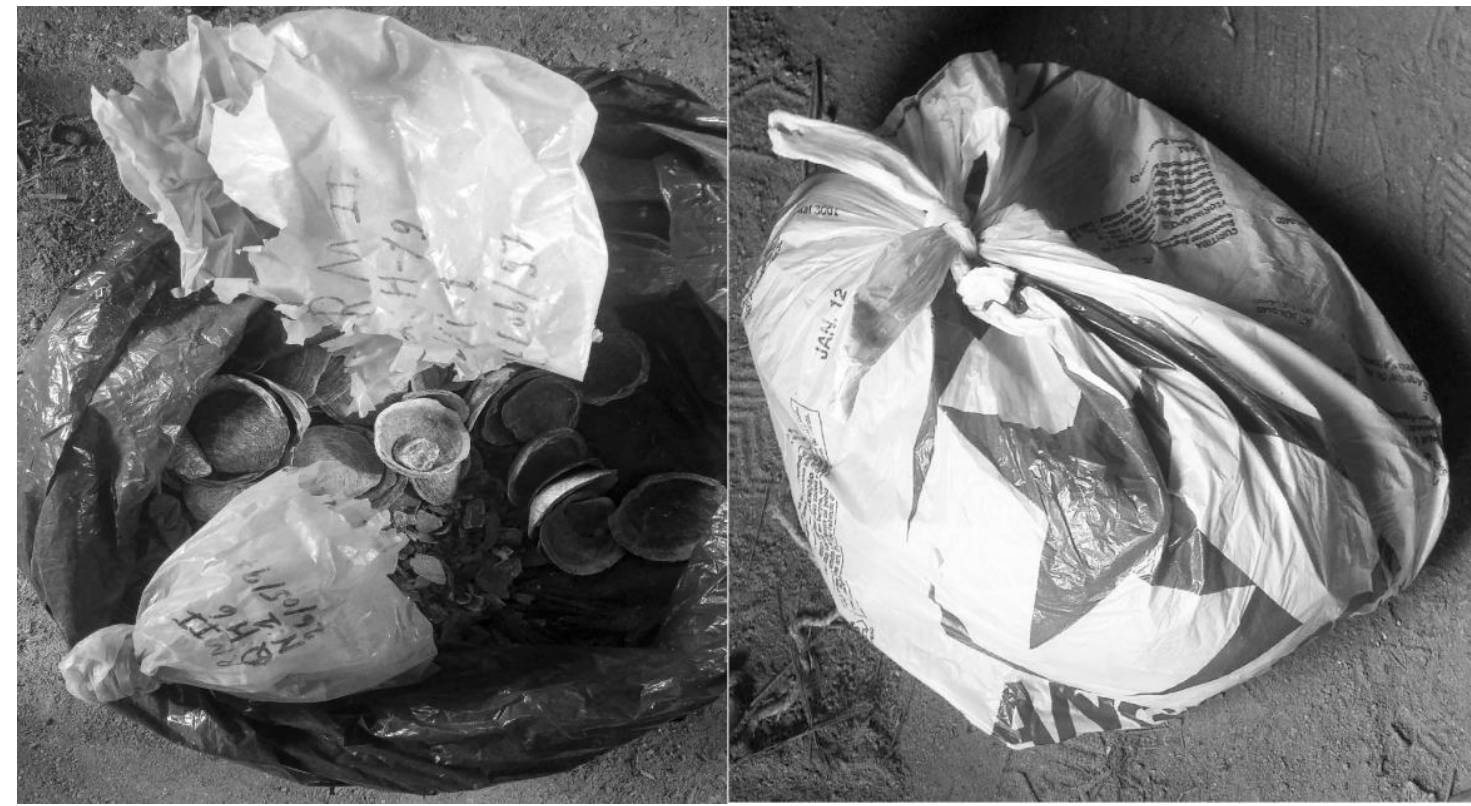

Figura 2: Sacos plásticos e/ou sacolas de mercado em que estão armazenados os vestígios coletados.

Foto: Letícia Gondim/Acervo: MArquE/UFSC (2017).

No relatório final de pesquisa, não há nenhuma informação sobre o critério de coleta do material, e os lixos recolhidos são os mais diversos, como espuma sintética, isopor, plástico, fragmentos de vidro, cerâmica atual, alumínio e alguns materiais orgânicos. 


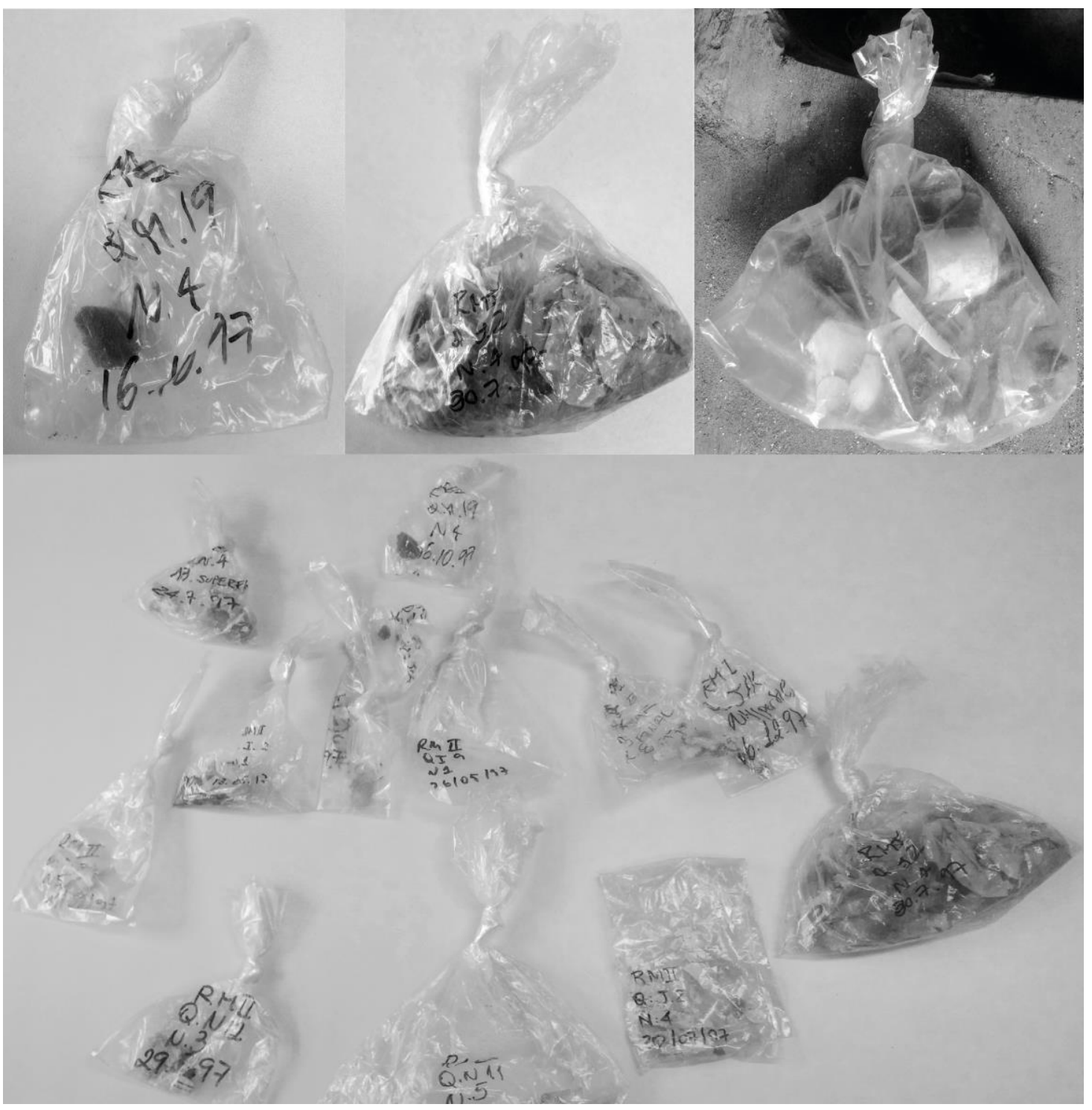

Figura 3: Vestígios de lixo contemporâneo coletados em campo, como possíveis sacolas plásticas, pedaços de espumas e cerâmica contemporânea.

Foto: Letícia Gondim/Acervo: MArquE/UFSC (2017).

Com relação ao material malacológico, o que mais chama a atenção é a quantidade. Para cada quadrícula, nível e dia de campo, havia, em média, um pacote de 500 gramas de conchas. Apenas dentro da reserva técnica do museu foram retirados $180 \mathrm{~kg}$ de conchas e, do Engenho, onde a maior parte do sítio permanece acondicionado, $683 \mathrm{~kg}$, totalizando 863 kg de conchas referentes a esse sítio e que estão armazenadas em sacos plásticos há vinte anos. 


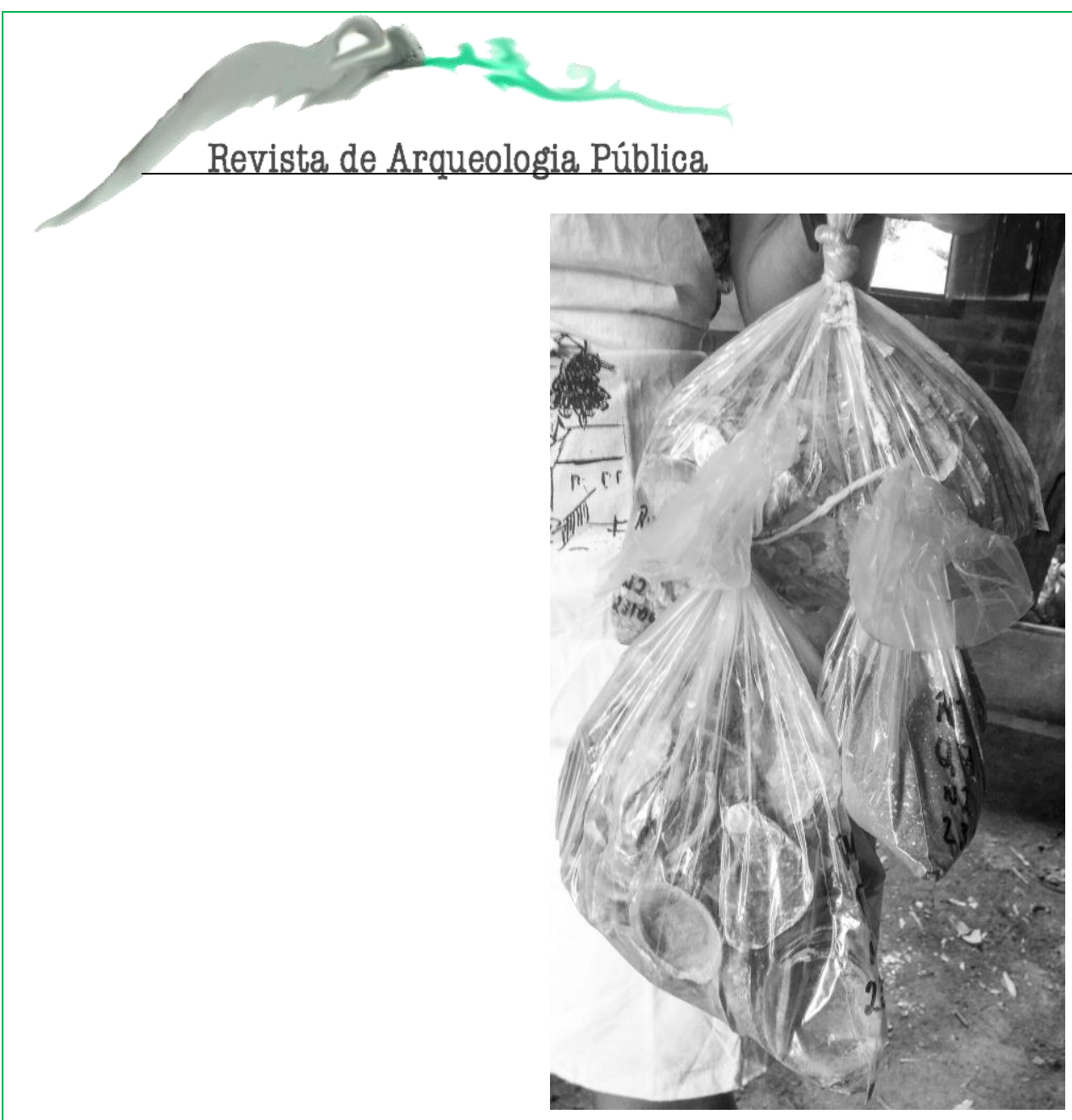

Figura 4: Exemplar de como encontramos armazenada a grande maioria dos pacotes de concha.

Foto: Letícia Gondim/Acervo: MArquE/UFSC (2017).

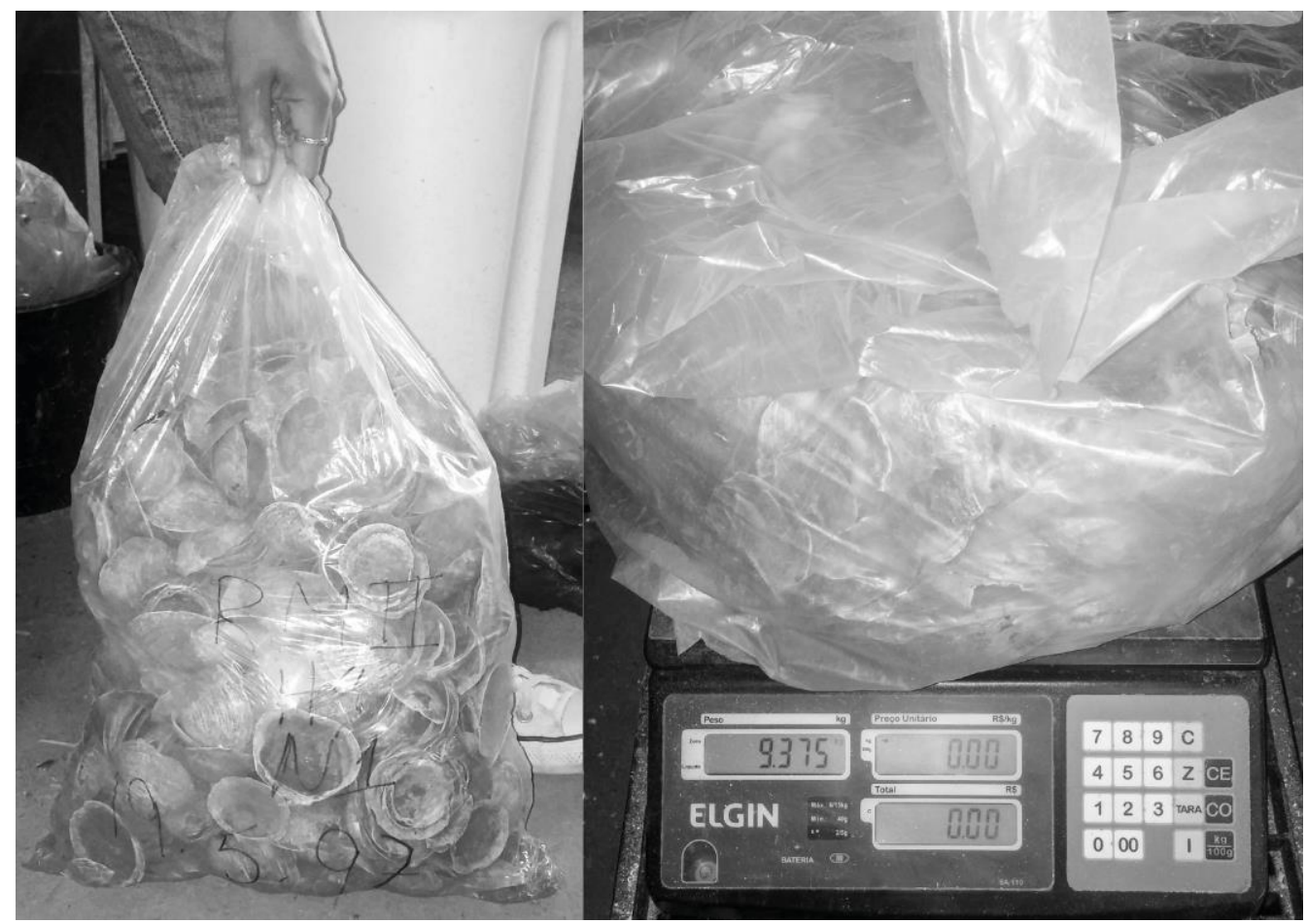

Figura 5: Pacote de concha. Na foto à direita, podemos ver seu peso de $9,375 \mathrm{~kg}$. Foto: Letícia Gondim/Acervo: MArquE/UFSC (2017). 


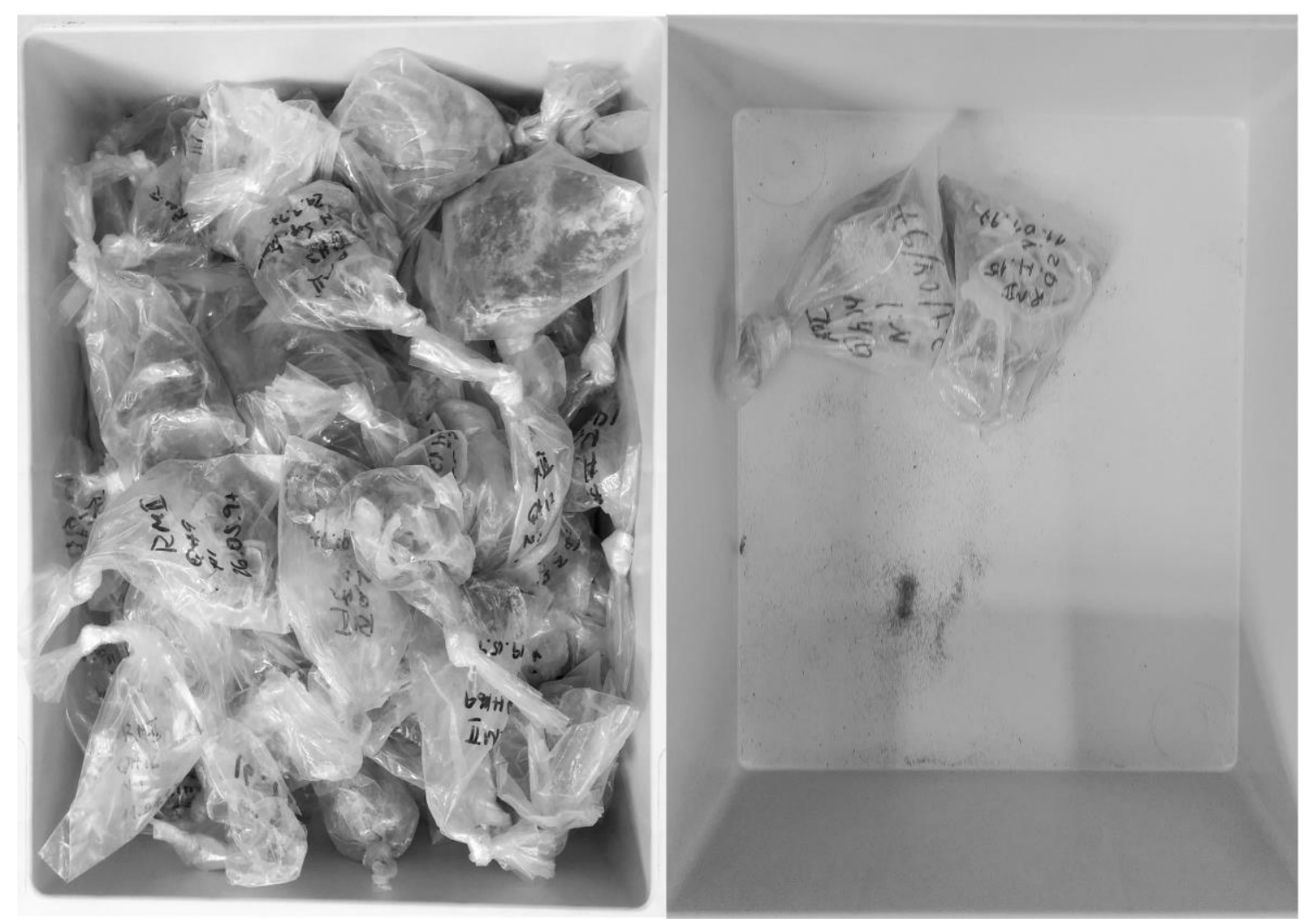

Figura 6: Na primeira imagem, caixa em marfinite contendo pacotes de concha localizada na reserva técnica do museu. Ao lado, depois da triagem, o espaço que foi liberado para acondicionamento do novo material.

Foto: Letícia Gondim/Acervo: MArquE/UFSC (2017).

\section{E AGORA, O QUE PODE SER FEITO?}

Em 2014, sob a coordenação da atual arqueóloga do MArquE, parte da equipe do Laboratório de Estudos Interdisciplinares em Arqueologia (LEIA/UFSC) inscreveram um projeto para concorrer ao Prêmio Elisabete Anderle de Estímulo à Cultura, Prêmio Catarinense de Museus Elisabete Anderle, Modalidade de Pesquisa, promovido pela Fundação Catarinense de Cultura (FCC).

Aprovado o projeto sob o título "Revisitando o acervo arqueológico do sítio Rio do Meio: estudo das coleções cerâmica, faunística e lítica", os envolvidos revisitaram, para novo estudo, parte da coleção lítica, cerâmica e faunística, bem como foi processado, documentado e acondicionado parte do acervo cerâmico e zooarqueológico. Deste projeto decorreu e ainda decorrem várias pesquisas, como o Trabalho de Conclusão de Curso (TCC) de Guilherme Burg Mayer e Letícia da Silva Gondim e a Tese de Doutorado de Simon-Pierre Gilson, além de artigos e apresentação de trabalhos em congressos. 
Como consequência do tema abordado na tese de doutorado de Gilson, realizamos uma triagem nos espaços onde se encontram acondicionados os vestígios faunísticos com o objetivo de selecionar as quadrículas eleitas pelo pesquisador para seu estudo. Foi durante a visita a esses espaços que separamos os pacotes de conchas, realizando rápida identificação das espécies e pesagem de cada pacote para possível descarte ${ }^{4}$, uma vez que a quantidade coletada excedeu a necessidade de pesquisa, abarrotando a reserva técnica, além de a maior parte não apresentar qualquer vestígio de transformação antrópica ${ }^{5}$.

Outra solução para o acervo malacológico, que não o descarte, e que vem sendo debatida pela equipe do museu, seria sua utilização para preencher caixas de escavação a serem empregadas em ações educativas. Além do mais, parte do acervo faunístico que não possui qualquer documentação de identificação de campo poderia, também, ser aproveitada como material didático. Uma solução equivalente poderia ser igualmente aplicada à parte do material lítico, que uma vez estudado, revelaram-se ecofatos, cuja a conservação em reserva técnica não tem justificativa. Destacamos que, atualmente, o MArquE está iniciando uma discussão sobre políticas de aquisição e descarte de seu acervo, previsto em seu Plano Museológico, que na época da escavação do sítio Rio do Meio este debate sequer existia.

\section{DISCUSSÃO}

No estudo de caso do acervo do Rio do Meio, houve a preocupação em realizar o salvamento do sítio arqueológico em sua totalidade do impacto que este sofreria. Porém, tal preocupação torna-se problemática, uma vez que boa parte do material continua acondicionada tal como chegou de campo, vinte anos atrás. Até que ponto resgatar sem processar é realizar um salvamento arqueológico?

Esta é uma pergunta que nos convida a refletir e, ao mesmo tempo, a criar formas de interação entre a pesquisa, a preservação e a proteção adequadas do patrimônio arqueológico, que quando retirado de seu contexto, é acondicionado e armazenado em reservas técnicas de museus (ARRIAZA; CASSMAN, 1988). É necessário o diálogo, bem como é imprescindível um planejamento que envolva profissionais da arqueologia, museologia e conservação para a criação de protocolos de coleta, entrada, guarda e

\footnotetext{
${ }^{4}$ O possível descarte dessas conchas somente será realizado com autorização do Instituto do Patrimônio Histórico e Artístico Nacional, Superintendência Regional de Santa Catarina (IPHAN/SC) e do Conselho Nacional de Arqueologia (CNA), respeitando as exigências destes órgãos no que tange ao material arqueológico descartado.

${ }^{5}$ Para técnicas adequadas de coleta de amostras, ver Scheel-Ybert (2006) e Klokler (2016).

\begin{tabular}{|l|l|l|l|l|l|l|}
\hline (c) Rev. Arqueologia Pública & Campinas, SP & v.11 & n.2 & p. 92 & Novembro/2017 & ISSN 2237-8294 \\
\hline
\end{tabular}
} 


\section{ARTIGO}

Revista de Arqueologia Pública

conservação das diferentes tipologias de acervo arqueológico, antes que este perca completamente seu potencial de investigação e difusão (ARRIAZA; CASSMAN, 1988).

É preciso ter políticas claras e planejamento a longo prazo que antevejam e evitem a deterioração que sofrem as coleções uma vez escavadas, pesquisadas e depositadas nos museus, caso contrário, como ressaltam Arriaza \& Cassman (1988), se estará cometendo um "arqueocídio". A responsabilidade de um arqueólogo não termina após a publicação de seu trabalho, esta preocupação deve ir muito além do interesse individual de pesquisa (ARRIAZA; CASSMAN, 1988).

Este artigo não tem como objetivo desqualificar o trabalho que foi realizado nem a instituição onde o próprio se encontra armazenado, mas chamar a atenção para o distanciamento que ocorreu entre o pesquisador, na época, e a instituição de guarda. Além disso, também chamamos a atenção para a divulgação das pesquisas para o grande público, pois muitas dessas publicações se encontram em periódicos, revistas especializadas e livros direcionados à academia sem que haja preocupação em informar a comunidade leiga.

Diante dos fatos acima apresentados, também cabe questionar a validade de uma coleta massiva de material, ao qual, após ser retirado de seu contexto, estudado ou não, acaba consumido em locais inadequados e propícios aos mais diversos fatores, como ataque biológico, saque e até mesmo destruição. Não podemos esquecer que ao retirarmos um objeto do solo e expô-lo, que de certa forma estava protegido, tal passa de um processo de lenta destruição para uma rápida degradação por conta das diferenças encontradas entre os distintos ambientes. Em outras palavras, a sensibilidade deste objeto está intimamente relacionada ao local de onde ele foi retirado com o novo ambiente ao qual será acondicionado (FRONER, 1995, p. 295).

Como bem lembrado por Froner (1995, p. 294), os bens patrimoniais arqueológicos e etnográficos brasileiros encontram-se em desigual posição em relação a outros produtos da cultura material. A autora também aponta que até mesmo a área da conservação se encontra dissociada do campo da arqueologia e que, no Brasil, as poucas escolas que existem priorizam o estudo de pinturas de cavalete e esculturas policromadas em detrimento de estudos voltados a artefatos arqueológicos e etnográficos. Se levarmos em consideração a posição que as profissões de arqueólogo, etnólogo e conservador ocupam no ranking científico, notamos certo distanciamento conceitual em relação aos trabalhos manuais concernentes às atividades de campo e de laboratório praticados por essas áreas. A visão que ainda se tem da arqueologia apenas como uma técnica, uma área auxiliar de outras disciplinas ainda sobrevive no meio acadêmico. Estas considerações têm ligação 
com a própria forma como as ciências sociais consideram qualquer trabalho braçal como atividade menor, herança da visão acadêmica implantada no Brasil (FRONER, 1995).

Porém, a própria área da arqueologia e etnologia cai na mesma postura preconceituosa dos cientistas sociais perante às demais áreas como museologia, curadoria, conservação e documentação de acervos ao tratar estas disciplinas como auxiliares, ferramentas de trabalho, sem levarem em consideração a interdisciplinaridade que nelas existem e que cada um delas pode dar sua contribuição para a preservação do patrimônio cultural (FRONER, 1995). Em contrapartida, a ausência de práticas que envolvam acervo arqueológico em cursos de graduação em museologia gera ainda mais tal distanciamento entre estes profissionais.

O conceito de interdisciplinaridade deve ser aplicado pelas distintas áreas em pesquisas que envolvam patrimônio arqueológico, sendo fundamental incluir nos currículos dos cursos de arqueologia, história, ciências sociais e áreas afins, relacionadas com o estudo do passado, as cadeiras de manejo de coleções e princípios básicos de conservação preventiva. Dessa maneira, como lembra Froner (1995, p. 296), as novas gerações "poderiam ser orientadas a proteger o patrimônio estudado, arqueológico ou não, percebendo-o globalmente, tanto em seus aspectos materiais quanto conceituais". Caso o debate acima tivesse sido incorporado por universidades, museus e outras instituições de pesquisa, problemas como o caso do sítio Rio do Meio seriam evitados.

Levar em consideração a questão da conservação perante os artefatos significa, a longo prazo, assegurar o potencial de investigação desses objetos coletados em campo, uma vez que esta ação demonstra a preocupação em manter a integralidade do material. $\mathrm{Na}$ falta de um conservador, um dos objetivos principais do arqueólogo deveria ser o desenvolvimento de estratégias de conservação. Isso porque ao expor os vestígios arqueológicos a condições diferentes, perturba o equilíbrio estabelecido entre os vestígios e o meio em que se encontravam, tornando-se, assim, um agente acelerador involuntário dos processos de deterioração e corrosão do material arqueológico e, desse modo, contribui para a destruição deste, embora os sítios arqueológicos não sejam bens renováveis (LÔREDO, 1994, p. 17). 


\section{ARTIGO}

\section{Revista de Arqueologia Pública}

\section{CONSIDERAÇÕES FINAIS}

Uma vez que o material coletado em campo chega à Instituição de guarda, este precisa ser armazenado em reservas técnicas adequadas garantindo longevidade e integridade ao acervo. Lamentavelmente, muitas instituições estão abarrotadas por quantidades massivas de artefatos arqueológicos de pesquisas passadas e, mesmo assim, algumas destas instituições continuam recebendo acervos de projetos atuais, que são armazenados em invólucros e ambientes de péssima qualidade.

Infelizmente a maioria dos museus possui pouco recurso e muitas necessidades, e embora a Instrução Normativa № 001 de 25 de março de 2015 ser clara sobre as responsabilidades do arqueólogo coordenador e da instituição de guarda e pesquisa, o que já foi realizado anteriormente à publicação desta Instrução está muito aquém de condições adequadas. Além disso, muitas pesquisas acadêmicas de décadas atrás não foram processadas em sua totalidade, e o resultado final de acervos arqueológicos herdados obviamente não é animador, ocasionando perda de informações, artefatos e contextos, resultando, assim, no amontoamento de objetos nos museus.

Não adianta que haja debates nas áreas de conservação, museologia e arqueologia, se não há uma equipe multidisciplinar coesa enriquecendo ainda mais o trabalho do arqueólogo, possibilitando, assim, a preservação e otimização dessas coleções. Um bom resultado foi a formação do Grupo de Trabalho em Arqueologia (GT Arqueologia) com a participação de diferentes profissionais de áreas distintas.

Embora no presente tenhamos mais órgãos, leis e portarias que nos assegurem que casos como o do Rio do Meio não se repitam, lamentavelmente o que foi feito está feito, e não há como voltar atrás. Lembrando, ainda, que temos, em todo o país, uma vasta coleção de acervo arqueológico e uma equipe reduzida de profissionais capacitados trabalhando nos museus, e, para piorar, uma equipe também reduzida dentro do IPHAN para garantir que fiscalizações sejam realizadas em tempo hábil.

Dessa forma, podemos concluir a importância de um trabalho planejado e bem executado durante as etapas de campo e laboratório, culminando em documentação, acondicionamento e armazenamento adequados dos materiais arqueológicos. Portanto, artefatos arqueológicos precisam ser preservados por meio de medidas de conservação que devem ser iniciadas em campo, posteriormente em laboratório e, finalmente, mantidos em reservas técnicas de museus. Caso contrário, o melhor que pode e deve ser feito é mantê-los enterrados no ambiente "estável" em que se encontravam, ao invés de armazenados de forma precária e inapropriada por meses, e mesmo anos, aguardando 
tratamento apropriado. A ação do tempo inevitavelmente modifica de algum modo a materialidade do objeto, mas os danos eventualmente produzidos por uma intervenção incorreta durante o processo de coleta podem ser piores.

O projeto contemplado no Edital Elisabete Anderle aqui referido teve como uma de suas propostas o estudo do acervo do sítio Rio do Meio a partir de diferentes abordagens e métodos interdisciplinares, gerando conhecimento arqueológico novo e, ao mesmo tempo, contribuindo para a conservação de uma coleção arqueológica única, colaborando para a valorização do potencial de estudo de acervos já existentes em Reservas Técnicas e fornecendo um exemplo positivo de pesquisa arqueológica realizada sem nova escavação. O propósito é chamar a atenção dos arqueólogos para o potencial e valor das coleções que estão depositadas em inúmeros museus, muitas das quais ainda não foram estudadas e merecem este tratamento, a exemplo do que aconteceu e está acontecendo com o acervo do sítio Rio do Meio. Ressaltamos que, graças ao prêmio, foram realizadas novas datações do sítio, que apresentava até o momento uma única data.

Sendo assim, graças à impulsão do projeto "Revisitando o acervo arqueológico do sítio Rio do Meio: estudo das coleções cerâmica, faunística e lítica", tornou-se possível dar continuidade às pesquisas iniciadas na década de noventa, viabilizando o processamento de parte significativa do material, produzindo conhecimento científico e readequação dos espaços de guarda e liberando as reservas técnicas da Instituição. Esperamos que esta iniciativa incentive a realização de pesquisas em acervos arqueológicos presentes em instituições museais, ao invés da escavação de novos sítios. 


\section{REFERÊNCIAS BIBLIOGRÁFICAS}

ARRIAZA, Bernardo; CASSMAN, Vicki. ¿Se esta produciendo um "arqueocidio"? Revista Chungará, no 20, julio 1988. Universidad de Tarapacá - Chile.

FOSSARI, Teresa Domitila. A População Pré-colonial Jê na Paisagem da llha de Santa Catarina. Tese (Doutorado em Geografia). 2004. Universidade Federal de Santa Catarina, Florianópolis, 2004.

FOSSARI, Teresa Domitila. O Salvamento do Sítio Rio do Meio: Projeto Gerenciamento dos Sítios Arqueológicos do Empreendimento Jurerê Internacional. Florianópolis, julho de 1998.

FRONER, Yacy-Ara. A conservação preventiva e patrimônio arqueológico e etnográfico: ética, conceitos e critérios. Revista do Museu de Arqueologia e Etnologia. São Paulo, 1995.

LESSA, A. Reflexões preliminares sobre paleoepidemiologia da violência em grupos ceramistas litorâneos: (I) Sítio Praia da Tapera-SC. Revista do Museu de Arqueologia e Etnologia, n. 15-16, p. 199-207, 2005.

LESSA, A.; SCHERER, L. Z. O outro lado do paraíso: novos dados e reflexões sobre violência entre pescadores-coletores pré-coloniais. Revista do Museu de Arqueologia e Etnologia, n. 18, p. 89-100, 2008.

LORÊDO, Wanda Martins. Manual de Conservação em Arqueologia de Campo. Rio de Janeiro: Instituto Brasileiro do Patrimônio Cultural. Departamento de Proteção, 1994.

MORAIS, J.L. Salvamento arqueológico na área de influência da PCH Moji-Guaçu. Rev. do Museu de Arqueologia e Etnologia, S. Paulo, 1995.

SCHEEL-YBERT, R. Proposta de amostragem padronizada para macro-vestígios bioarqueológicos: antracologia, arqueobotânica, zooarqueologia. Revista do Museu de Arqueologia e Etnologia, n. 15-16, p. 139-163, 2006, 2005.

SCHERER, Luciane Zanenga. Acervos e Museus: Diálogos entre Arqueologia e Museologia. Revista Eletrônica Ventilando Acervos, v. 4, n.1, dez. 2016, Florianópolis: MVM. 